\title{
THEORETICAL ASPECTS OF LOGISTICS TRAINING PROCESS MANAGEMENT
}

\author{
Ramūnas Palšaitis ${ }^{1}$, Darius Bazaras ${ }^{2}$ \\ Dept Transport Management, Vilnius Gediminas Technical University, \\ Plytinès g. 27, LT-10105 Vilnius, Lithuania.E-mails: ${ }^{1}$ trvadyba@ti.vtu.lt; ${ }^{2}$ dbazaras@vv.vtu.lt
}

Received 30 July 2006; accepted 4 December 2006

\begin{abstract}
Authors discuss about main training needs and problems in the logistics as main driving motive for learning and training process organization in the universities and at the non-formal training places - work places, courses and training organizations. All driving motives can be named as internal and external forces which influence persons. In many cases external driving motives are related to person's "positive pushing" direction, for example, integration and globalization process in business or implementation of the new technologies. The internal driving motives sometimes are related to problematical points of training, i. e. negative self-estimation, negative view of environment and bad understanding of knowledge's benefits in the person's practical life. The main problems and perspectives of logistics training process are named in this article. Main reasons for training process, methodology and training costs are described.
\end{abstract}

Keywords: logistics training, formal and non-formal education, training process, problems of training process, training cost, personnel management.

\section{Introduction}

Companies are trying to score an advantage against their competitors. Companies' managers chunk their time thinking about the directions in which their company must develop. They try identifying the tasks which must be realized. Without good coordinated team work it can't be realized. Managers must think about how personnel should change its work and how employees should interact in relationships. More and more companies' owners or leaders understand that manpower may be important, and that it may be sensible to begin to consider how they can assist the personnel to perform to the peak of their potential. Accepting that personnel are important means more attention must be given to learning and training.

Since the first years of Lithuania's independence, the image of the country is being established as a transit and logistics service country, which by international transport corridors connects Western and Eastern, as well as Southern and Northern European countries. This was predetermined by the importance of possible logistics services which can be proposed for the local and foreign companies. Incomes from logistics services create major part of the country's GDP and establish thousands of working places.

\section{Training needs}

As a result of the new situation after Lithuania's accession to the EU on 1 May 2004 service trade and industrial companies had to prepare a mental strategy how to respond. The biggest part of companies' business strategy was based upon their existing skills and knowledge, their experience and their standards of work. Part of companies' managers recognized that this feedback is unsuitable. This was the first key stage in learning.

The second key stage is being willing to change. If they understand needs to change, they have a motivation to learn. If they have a motivation to learn, the next step is to help them build a vision of a new business strategy, and then to construct an action plan of how it can be achieved.

Implementation plan can help people to change their approach, which should then result in changing their actions and behaviour. At this stage Lithuanian medium-level and top-level managers started to participate in the different seminars and training courses in Lithuania and abroad. The result was/is personal growth for the individual and improved business performance in the companies providing logistics services.

It is important to examine some business and development trends that will create the environment for logistics activities in Lithuania.

There exist ranks of reasons which are stimulating training process in logistics.

Integration into $\boldsymbol{E} \boldsymbol{U}$ and globalization. All large Lithuanian and foreign companies have an international aspect in their supply chains which cover Europe and wider markets. Implemented contemporary information technologies safeguard that new products and services would receive international exposure much more quickly. 
This means that logistics companies located in Lithuania are exposed to international competitors more quickly.

Company management structures. Supply channels are changing all the time and the company's organization structures must be transformed from time to time. Companies do quite many organizational changes for themselves, and there is an increasing reliance on outsourcing partners. The ability to maximize such relationships will be a source of advantages.

New technologies. The use of modern technologies in logistics is becoming more and more prior. Few major technology changes have a significant impact on logistics activities: wide application of multimodal cargo transportation, implementation of modern applied information technologies and EDI. Application of ebusiness, which enables logistics services providers to work more closely on a collaborative basis with other supply chain partners. New technologies are especially significant to the transport and warehousing services providing companies.

Business performance. It is identified that modern business performance is oriented to the high-level professional employees. New technologies replace hackwork and more and more people are moving towards jobs that are adding more value and hence have the capability to be competitively important. The speed of change will be influenced by the capability of employees to absorb new ideas. Currently in Lithuania companies are competing between themselves for the university graduates who have diplomas in transport management and logistics.

Better relationships with customers and competitors. There is evidence of increasing emphasis on the development of internal and external relationships, moving from confrontation with competitors to collaboration and teamwork.

Competitive advantage. Competitive advantage will increasingly involve using information, knowledge and manpower. The traditional sources of logistics advantages such as 7R (Right place, Right time, Right consumer, Right price...) are becoming very visible, very quick, and their ability to deliver sustainable advantage is limited. Knowledge, information and the way we manage and organize people are invisible, posing greater challenges to competitors who seek to copy.

Logistics service development. As a new example of logistics service development could be Logistics centers. A logistics center can be set up only in some particular place out of the finite set of possible locations, which requires additional costs. The system also involves costs to satisfy the customer's demands from some of the available logistics centers, depending on the number of requirements. The goal is to minimize overall costs of the system. So, we have a difficult combinatorial problem of determining the number of logistics centers [1].

\section{Problematical aspects of the training process}

During analysis of lifelong learning process we have identified that this process has a positive and a negative side. Learning organization process is faced with singularity, in the work place learning particularly. Some authors notice that there are many features of the learning organization model that make it attractive to the persons who are interested in lifelong learning, such as it is broadly emancipatory and language inclusive and there is emphasis on organizational goals that transcend the pursuit of short-term profit maximization. The role of the teacher/lecturer and of his qualification in teaching process is already recognized at policy level.

According to Jim Gallacher (Glasgow Caledonian University) and Fiona Reeve, (Open University) if we want to explore question about informal learning in the work place, from the perspective of the employees, we will draw on the findings of a research project undertaken by Eraut et al (1998) as part of the ESRC funded Learning Society Programme. Their study focused on the development of knowledge and skills in employment and involved 120 people with different life, job and education experience. Interviews were conducted to explore what types of knowledge and skills the participants used in their work activities, how they acquired the capacity to do what they did, and what factors had affected their learning process. Their findings are stark, suggesting that formal education and training provided only a small part of what is learned and used at work. Most of the learning described in their interviews was non-formal, neither clearly specified or planned (Eraut et al, 1998). They suggest as a consequence that dominant assumptions underpinning policy for "The Learning Society", stressing the importance of formal provision, need to be balanced by an understanding of the value of informal learning "on-the-job" and the factors which affect it. (Jim Gallacher, Glasgow Caledonian University, Fiona Reeve, Open University).

These authors provide an important role of universities in the practical education process. The universities have to work more closely with employers in contributing to the processes of economic change and development. It is expected that universities must be more flexible in their modes of delivery for meeting the lifelong learning agenda. The role of an increasingly wide range of organizations and agencies for meeting learning needs has been emphasized. This creates a potential threat to the role of universities at this important time of change, and the recognition, on their part, of the need for adaptation and change if they are to avoid being marginalized with respect to some of these key areas of development. (Jim Gallacher, Glasgow Caledonian University, Fiona Reeve, Open University).

According to Jim Gallacher and Fiona Reeve, policy has been actively seeking to bring together the two relatively separate spheres of the workplace and higher education, contributing to the "blurring of boundaries" which has been identified as characteristic of moves towards lifelong learning (Edwards, 1997). Work-based learning is positioned as a radical disruption of the traditional boundaries between the academy and work, leading to new types of engagement and different kinds of relationships [2-4]. 
When we are talking about problematical points in the logistics training process, especially when this process is organized for adult or employee, we have to notice four groups of problems which arise during this process:

\section{- $\quad$ psychological influence and life experience; \\ - person's relations with other persons; \\ - commercialization of the training activity; \\ - motivation (see Fig 1).}

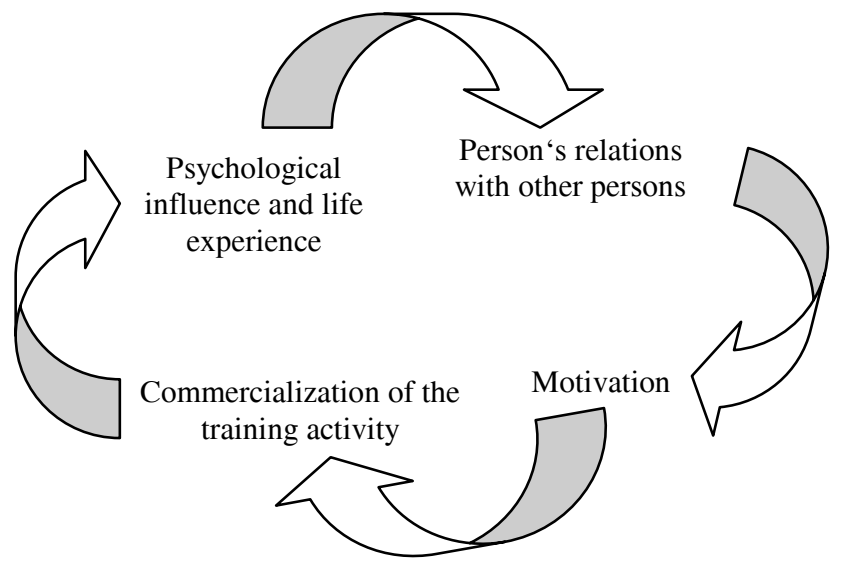

Fig 1. Model of problem fields in the training process

Firstly, we can name psychological influence and life experience problems. These problems are arising from different person's life positions and environment influence on him.

The second group of problems in training process deals with person's relations with other persons, especially with trainers and teachers. Sometimes we can hear replications from adult students classroom "...our professor is much younger than us..." This example shows that some persons cannot change their subjective view on the trainer's age and his experience. It is difficult enough because it is related with person's personality limitation and stereotype thinking mode. This barrier can create a situation when training process becomes impossible though the trainer is competent enough.

During the last years a new problem arises, which is related with commercialization of the training activity. Many consultancy and training firms are organizing miscellaneous one-two days training courses and during these courses they are using much more non-formal education methods or group management methods which cannot compare with formal education facilities. Participation in these courses is very attractive and pleasant for the participants because the use of these methods can create comfort and safety atmosphere but can not convey systematic knowledge. Training process commercialization is connected with "syndrome of consumer society". It means that some training process participants are thinking that if they pay money, they will become competent automatically or believe, that somebody knows about "super technologies" that could be understood and implemented during lunch-hour. Unfortunately, but this point of view is still actual and some consultancy firms which want to avoid conflicts between clients and themselves pay more attention to the "show" but not for deep knowledge.

From another point of view, we cannot reject the role of group management methods during the training process. If students are playing role of "students" and lectors are playing role of "lectures" without motivation and internal power - it is the best way to failure. Motivation is the most important point in the training. Participants must understand that they are not "players for fun", and they can receive benefit from knowledge which they are getting during the training process.

These problems are related to:

- $\quad$ insufficient teaching methodology;

- $\quad$ insufficient flexibility;

- bad understanding of structured knowledge's role in the education process;

- bad understanding of knowledge's benefits in the practical life.

Finally, the biggest part of these problems can be resolved by complex decisions which can create transformation: data $\rightarrow$ information $\rightarrow$ knowledge (see Fig 2). It means that everybody can collect data, but data are not useful without perceptions. If data are perceived, they are becoming information. Unfortunately but many consultancy firms like to stop on this step. Information is important enough but if a person cannot use this information for his business or life tasks and create added value - information is a filled sketchbook only. Knowledge is information which can be used for creation of added value in the person's business and personal life and all institutions which have relations with training activities have to provide this task.

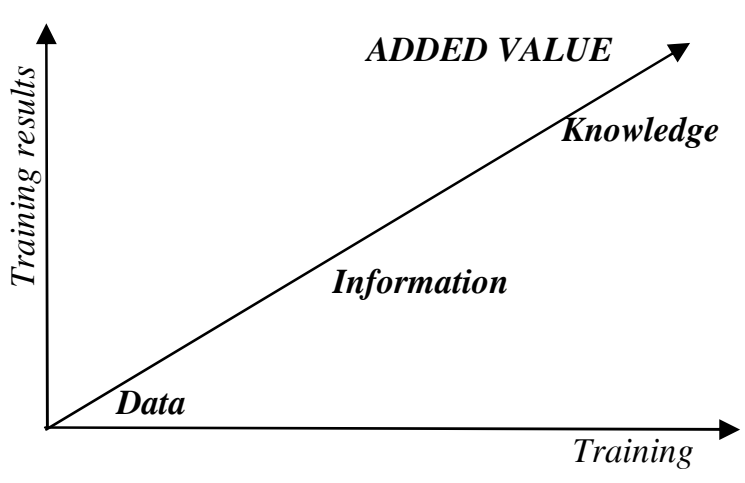

Fig 2. Model of problems resolving decision in the training process

\section{Institutions' role in the training process}

Department of Transport Management of Vilnius Gediminas Technical University has a tradition of educating engineers for a wide range of technology-related fields. Adding a managerial and economic dimension to the engineering education may create more opportunities for the graduates in the job market. It is very important to mention that Department's students expect to graduate having acquired not only "soft" managerial skills, and "theoretical" knowledge of economics and business administration, but also the solid ground for 
the real profession in transport engineering. It will be noted although that this combination of technology, management and economics may be also achieved in other, perhaps more suitable and sustainable ways too.

Transport is a significant sector of the Lithuanian economy and its importance continues to grow with Lithuania becoming a "border" country of the EU. This is reflected also in national long-term strategic objectives of economic development. The increase in the number of transport companies and their capacity are creating favourable prospects for specialists, who are able to manage the resources in this field. Also, in the public sector, both at municipal and national level, there is a need for proper coordination, planning and control of transport-related services. The graduates of the programme have confirmed that they have not faced any difficulties in finding jobs after their graduation. Also the employers expressed their satisfaction with the ability of the graduates to integrate quickly into the work environment.

The curriculum contains the fundamental knowledge required of higher education programmes, in general and that is required to train management specialists, in particular. The integration of theoretical and practical knowledge is also appropriate. What concerns the content of the courses they seem to follow reasonably closely the international tendencies. The list of recommended literature, however, does not always contain the textbooks that are most often used in similar courses in other European countries. The basic economic, managerial and methodological courses should especially be revised and improved in this respect.

The sequence of the courses seems on the die of whole logical and appropriate, except perhaps for the introductory microeconomics and macroeconomics, which enter into the curriculum in the second year (III and IV semesters) only. The ratios of the general and the professional specialisation courses seem appropriate, although most courses in economics and business tend to be unnecessarily over-specialised towards the transportation sectors.

The curriculum is comprised overwhelmingly of compulsory courses. There is very little room left for electives (less than 10\%), and the number as well as the range of electives is also rather limited.

Advantages of the Department's programme:

- $\quad$ the programme provides highly skilled bachelors for the transportation sector providing them with sufficient knowledge in the areas of business administration and economics combined with the technological specificities of the transport areas;

- the programme satisfies the requirements of the overall regulations and requirements;

- the programme has a sufficient number of professionally well-trained academic staff;

- a significant part of the faculty is engaged in applied research;

- there is a demonstrated need for and support of the programme in Lithuania.

\section{Disadvantages:}

- the programme is overspecialized, focuses on a relatively narrow area;

- there is not enough flexibility in the curriculum (small number and narrow scope of effectives);

- the faculty is not equipped sufficiently with the modern theories and practices of business administration and management, especially in areas beyond transport management;

- the number of weekly hours in class is on the whole too large.

As a good example of non-profit training could be LINAVA Training center which was established by the Lithuanian National Road Carriers Association (LINAVA) in 1997. The task of the Center is to provide high quality training and consulting services to the members of association, i. e. international freight transport companies and passenger operators. Along with the members, all other road transport companies both international and domestic successfully use the services of the Center. The Center is involved in training and improvement of professional competence of all specialists employed in road transport enterprises. They are able to master their knowledge in road transport law, CPC for managers of freight and passenger companies, ADR, DGSA, TIR procedures, AETR, ATA, ATP, transportation of live-stock and a number of other subjects related to transportation by road.

The Center strives to take a leading position in road transport training and consulting market of Lithuania. It has well-equipped modern facilities. Up to 2000 participants take part at training courses annually. The Center is approved to provide training in ADR and DGSA. It is also a certified Travel Agency and organizes group visits to international transport and logistics fairs, trainings and seminars abroad. Traditional are visits to fairs in Moscow, Munich, Amsterdam, Hanover, Poznan, St. Petersburg. For road transport enterprises the center organizes presentations of new products that might be of their interest such as oils, tires, spare parts, etc [5].

\section{Logistics training costs}

Training is frequently perceived as being expensive. Training can be expensive if it is badly planned, badly organized, badly conducted and badly controlled.

It is important to identify all of the costs associated with training. These are:

- $\quad$ training costs;

- $\quad$ ignorance costs;

- $\quad$ lost opportunity costs.

Training costs. These costs can be broken down into five areas:

- Analysis costs: associated with the initial problem identification, needs analysis and development of objectives. They will include salaries, materials and consulting fees.

- Development costs: directly related to the programme development. These costs are usually 
substantial, but could be spread over several runnings of the programme if the assignment allows.

- Delivery costs: include all the costs associated with delivery of the programme, including materials, accommodation, salaries and expenses of participants, instructor fees and equipment rental.

- Evaluation costs: include the evaluation material and the time to administer the evaluation, analyse the results and report the findings.

- Transfer costs: include all the costs of providing the transfer work to ensure that there is a conducive training climate.

Ignorance costs. These costs can be broken down into two categories. The first is costs of failure, which covers the costs of correcting mistakes both internally to the business and externally with customers.

The second category is costs of exceeding requirements. These are incurred for providing services for which no known requirement exists. Examples include excess stocks, extra transport cost of quicker delivery, excess cost of inappropriate distribution network, and excess cost of under-utilization and performance of resources.

Lost opportunity costs. Costs of lost opportunities are reflected in the profit impact of the lost revenues resulting from cancellation of orders or lost business, as a consequence of the actions of the logistics department. These occur as a result of not delivering in time or not having stock available. Before training commences there is likely to be considerable waste in the form of ignorance and lost opportunity costs [6].

\section{Conclusions}

1. All driving motives can be named as internal and external forces which influence persons. In many cases external driving motives are related to person's "positive pushing" direction, for example, integration and globalization process in business or implementation of the new technologies. The internal driving motives sometimes are related to problematical points of training, i. e. negative selfestimation and bad understanding of knowledge's benefits in the person's practical life.

2 . In the logistics training process we face with psychological influence and life experience, person's relations with other persons, commercialization of the training activity and motivation problems, all relating together. In many cases, commercialization of the training activity is connected with the desire of commercial firms to avoid conflicts with commercial training course participants. For this reason firms are trying to use more non-formal education methods in- stead of formal education methods which are more difficult and not attractive. For this reason quality of training process and knowledge become worse.

3. For achieving quality of training process it is necessary to understand the role of transformation from information to knowledge. It is very important to show real benefits of knowledge used for the person's business and/or personal life. This can help to create deeper motivation of participants and teachers (trainers). Participation and combinations of formal and non-formal education institutions in the training process are welcome.

4. Notion Training quality is connected with methodology of the training organization and used for learning methods. It is very important to note that training process must have orientations to real person's needs and systematical knowledge's conveyance which are related to time resources.

5. Training is frequently perceived as being expensive. Training can be expensive if it is badly planned, badly organized, badly conducted and badly controlled. It is important to identify all costs associated with training. These are: training costs, ignorance costs, lost opportunity costs. All training costs must be provided and well-managed by training organizations. Participants of the training process have to understand the role of training costs as well.

\section{References}

1. KLAPITA, V.; ŠVECOVÁ, Z. Logistics centers location. Transport, 2006, Vol XXI, No 1, p. 48-52. ISSN 16484142.

2. GALLACHER, J.; REEVE, F. Work-based learning: the implications for higher education and for supporting informal learning in the workplace. www.open.ac.uk/lifelong-learning/papers/, visiting date January 2006. 15 p.

3. ZUKAS, M.; MALCOLM, J. Pedagogies for lifelong learning: building bridges or building walls? University of Leeds. www.open.ac.uk/lifelong-learning/papers/, visiting date January 2006, $11 \mathrm{p}$.

4. JANSSENS, J. Innovations in lifelong learning. Capitalising on ADAPT. Cedefop Panorama series; 25. Luxembourg: Office for Official Publications of the European Communities, 2002, 115 p.

5. www.linava.lt

6. PALŠAITIS, R.; BAZARAS, D. Prospective of logistics training in Lithuania. Transport and Telecommunication, 2006, Vol 7, No 2, p. 390-397. ISSN 1407-6160. 